\title{
冷蒿酚酸及其抗氧化防御酶活性对机械损伤的响应
}

\author{
刘盟盟 贾 丽 $^{1}$ 程路芸 ${ }^{1}$ 张洪芹 ${ }^{1}$ 藏晓琳 $^{1}$ 宝音陶格涛 $^{2}$ 张汝民 ${ }^{1}$ 高 岩 $^{*}$
}

${ }^{1}$ 浙江农林大学亚热带森林培育国家重点实验室培育基地, 浙江临安 311300; ${ }^{2}$ 内蒙古大学生命科学学院, 呼和浩特 010021

\begin{abstract}
摘 要 为了探讨放牧过程中冷蒿(Artemisia frigida)酚酸及其抗氧化酶活性对牲畜采食和践踏损伤的响应, 该研究对盆栽冷 蒿幼苗枝叶采用不同程度(轻度、中度和重度)机械损伤的方式模拟放牧强度, 利用高效液相色谱技术测定了机械损伤处理 $6 \mathrm{~h}$ 后冷蒿枝叶和根系 9 种酚酸含量的变化; 同时对多酚氧化酶(PPO)、苯丙氨酸氨裂合酶(PAL)和抗氧化酶活性进行了测定, 分 析了酚酸含量与PPO和PAL活性之间的相关性。结果表明: 轻度机械损伤可以诱导冷蒿枝叶和根系中PPO、PAL和抗氧化酶 迅速做出响应, 活性显著升高; 随着机械损伤强度增加, 冷蒿枝叶游离态咖啡酸、丁香酸、阿魏酸和肉桂酸含量显著增加, 与 对照相比中度损伤处理分别增加了 $150.4 \% 、 93.5 \%$ 、154.4\%和121.7\%, 与PAL活性呈正相关关系; 游离态绿原酸和邻苯二酚 含量减少, 与对照相比重度损伤处理后降低了 $91.1 \%$ 和 $69.3 \%$, 与PPO活性呈负相关关系; 与对照相比重度损伤处理下没食子 酸和原儿茶酸分别增加了 $280.6 \%$ 和 $215.7 \%$ 。随损伤强度增加, 根系中9种游离态酚酸含量均显著增加, 其含量均小于叶片。 机械损伤导致冷蒿枝叶中游离态和结合态酚酸总量增加, 根系中结合态酚酸减少。上述结果表明机械损伤首先诱导冷蒿体内 应激防御系统中抗氧化酶和酚酸合成关键酶活性升高, 然后促进抗氧化物质酚酸的积累, 调节冷蒿植株内木质素合成以及醌 类和单宁形成, 增强冷蒿抗机械损伤能力和提高冷蒿的耐牧性。
\end{abstract}

关键词＼cjkstart冷蒿; 机械损伤; 酚酸; 抗氧化酶; 苯丙烷代谢

引用格式: 刘盟盟, 贾丽, 程路芸, 张洪芹, 藏晓琳, 宝音陶格涛, 张汝民, 高岩 (2017). 冷蒿酚酸及其抗氧化防御酶活性对机械损伤的响应. 植物生 态学报, 41, 219-230. doi: 10.17521/cjpe.2016.0161

\section{Responses of phenolic acid and defensive enzyme activities to mechanical damage in Artemisia frigida}

LIU Meng-Meng ${ }^{1}$, JIA Li ${ }^{1}$, CHENG Lu-Yun ${ }^{1}$, ZHANG Hong-Qin ${ }^{1}$, ZANG Xiao-Lin ${ }^{1}$, BAOYIN Taogetao ${ }^{2}$, ZHANG Ru-Min ${ }^{1}$, and GAO Yan ${ }^{1 *}$

${ }^{1}$ The Nurturing Station for the State Key Laboratory of Subtropical Silviculture, Zhejiang Agriculture and Forestry University, Lin'an, Zhejiang 311300, China; and ${ }^{2}$ College of Life Science, Inner Mongolia University, Hohhot 010021, China

\section{Abstract}

Aims The study aims at understanding the effects of feed intake and trample damage on the phenolic acid formation and antioxidant enzyme activities in Artemisia frigida, and elucidating the adaptive mechanisms in A. frigida to grazing in secondary metabolites and their related enzyme activities.

Methods We analyzed the phenolic acid content and the activities of polyphenol oxidase (PPO), phenylalanine ammonia-lyase (PAL) and protective enzymes in leaves and roots in A. frigida under three levels (light, moderate, and heavy) of manipulative grazing condition. The measurements of the 9 phenolic acid contents started after $6 \mathrm{~h}$ of the mechanical damage of the plants by using the high performance liquid chromatography (HPLC), and the enzyme activities in leaves and roots were measured by a spectrophotometry method.

Important findings The light damage treatment induced productions of PPO, PAL and significantly $(p<0.05)$ increased antioxidant enzyme activities in the leaves and roots of A. frigida. The contents of PPO, PAL and antioxidant enzymes increased with increasing intensity of mechanical damage. Compared to the control, the content of free caffeic, syringic, ferulic and cinnamic acid in the leaves $A$. frigida were significantly elevated $(p<0.05)$ by 150.4\%, 93.5\%, $154.4 \%$ and $121.7 \%$, respectively. They were significantly $(p<0.05)$ positively correlated with PAL activity in the moderate damage treatment. The content of free chlorogenic acid and catechol decreased by $91.1 \%$, and $69.3 \%$, respectively, compared with the control they had a negative correlation with PPO activity in the heavy damage treatment. The contents of gallic and protocatechuic acids increased $(p<0.05)$ by $280.6 \%$ and $215.7 \%$, respectively, in the heavy damage treatment. With increasing intensity of mechanical damage, the content

收稿日期Received: 2016-05-07 接受日期Accepted: 2016-12-25

* 通信作者Author for correspondence (E-mail: gaoyan1960@sohu.com) 
of 9 free phenolic acids significantly increased in roots but the increasing range was less than the one in leaves. Mechanical damage induced an increasing trend in the total amount of free and bounded phenolic acids in the leaves but a decreasing trend in the total amount of bounded phenolic acids in the roots of $A$. frigida. The results indicated that mechanical damage could firstly induce an increase of antioxidant enzymes and key enzymes in phenolic metabolism in A. frigida, leading to the accumulation of antioxidant substances of phenolic acids, further regulate the biosynthesis of lignins, quinones and tannins, and then enhance the resistance to mechanical damage and improved the tolerance of $A$. frigida to grazing.

Key words Artemisia frigida; mechanical damage; phenolic acid; antioxidant enzyme; phenylpropanoid pathway

Citation: Liu MM, Jia L, Cheng LY, Zhang HQ, Zang XL, Baoyin T, Zhang RM, Gao Y (2017). Responses of phenolic acid and defensive enzyme activities to mechanical damage in Artemisia frigida. Chinese Journal of Plant Ecology, 41, 219-230. doi: 10.17521/cjpe.2016.0161

诱导防御机制在植物自我保护过程中发挥着重 要的作用, 机械损伤或动物取食都会诱导植物体内 产生大量的防御物质(Kessler \& Baldwin, 2002; van Poecke \& Dicke, 2004)。植物通过次生代谢途径产生 大量挥发性有机化合物(VOCs)、酚酸、单宁等重要 的化学防御物质, 增加植物的防御能力, 对外界刺 激做出响应(Agrawal, 2001)。酚酸是植物体内广泛 分布的一类次生代谢产物, 其结构复杂, 种类繁多, 游离态酚酸参与很多生理过程, 如抗氧化、清除自 由基、形成木质素、刺激反应和毒素活性的反应等 (Brandolini et al., 2013), 结合态作为储藏形式。酚酸 是植物体内通过苯丙烷酸代谢途径产生的一类重要 物质, 直接参与植物的防御反应(Matkowski, 2006)。 多酚氧化酶(PPO)和苯丙氨酸氨裂合酶(PAL)是苯丙 烷酸代谢途径中两个重要的关键酶, 直接调控酚酸 形成量和增加细胞壁木质素抵抗机械压力。因而, PAL 和PPO活性的提高是诱导防御物质产生和增加 防御能力的重要前提(Winkel-Shirley, 1999; Latha et al., 2009)。诸多研究表明, 植物受到损伤或动物采 食后, 能够激活植物的防御反应, 诱导体内 PAL和 PPO活性显著升高(Chaman et al., 2003; Koussevitzky et al., 2004), 合成并积累酚类化合物(Gogoi et al., 2001; 胡增辉等, 2009; 严善春等, 2010)。超氧化 物歧化酶(SOD)、过氧化物酶(POD)和过氧化氢酶 (CAT) 是植物体内主要的抗氧化酶和活性氧清除剂, 参与植物防御反应(Sharma et al., 2012)。目前, 机械 损伤诱导植物酚酸积累和抗氧化酶活性研究多限于 地上部分, 但是, 植物生长过程中, 地上和地下是 一个协调、统一的生命整体, 丛生禾草的再生生长 研究表明, 根系会对刈割做出生理响应, 通过调节 生长和生理代谢, 增强植物的抵抗能力(章家恩等,
2005; Puthoff \& Smigocki, 2007)。

冷蒿(Artemisia frigida)为菊科蒿属多年生小半 灌木, 广泛分布于内蒙古草原带和荒漠草原带, 是 草原群落的主要建群种。在连续多年过度放牧压力 下草原退化演替为以冷蒿为主的单一优势群落(王 炜等, 1996; 汪诗平等, 2001)。近年来, 对冷蒿的研 究主要集中在群落结构特征(李衍青等, 2011; 赵康 和宝音陶格涛, 2014)、营养胁迫(刘娜娜等, 2014)、 化感作用(张汝民等, 2010; 左照江等, 2010)以及冷 蒿挥发物对家畜采食的影响(Zhang et al., 2014)等方 面, 但是关于冷高耐损伤机理以及酚类化合物代谢 对放牧损伤的响应机制鲜见报道。本研究以冷蒿为 试验材料, 研究了不同强度机械损伤对冷蒿枝叶和 根系中 9 种游离态和结合态酚酸含量的影响, 以及 苯丙烷酸代谢调控酶(PPO、PAL)和抗氧化酶(SOD、 POD和CAT) 活性的变化, 揭示冷蒿应激防御反应 系统中酚酸合成和抗氧化酶的生理响应调控机制, 以及冷蒿抗机械损伤的适应对策; 同时为牧场的合 理利用、退化草地恢复、草地生物多样性保护以及 可持续发展利用提供参考。

\section{1 材料和方法}

\section{1 试验材料}

试验材料冷蒿采自内蒙古自治区锡林浩特毛 登牧场内蒙古大学草地生态学研究基地, 地理位置 $44.17^{\circ} \mathrm{N}, 116.48^{\circ} \mathrm{E}$, 海拔 $1160 \mathrm{~m}$ 。全年平均气温为 $-0.4{ }^{\circ} \mathrm{C}$, 最冷月 $\left(1\right.$ 月)平均气温 $-22.3{ }^{\circ} \mathrm{C}$, 最热月 $(7$ 月)平均气温 $18.8{ }^{\circ} \mathrm{C}, \geqslant 0{ }^{\circ} \mathrm{C}$ 年积温为 $2410{ }^{\circ} \mathrm{C}$, $\geqslant 10{ }^{\circ} \mathrm{C}$ 积温为 $1597.9{ }^{\circ} \mathrm{C}$, 无霜期 91 天, 草原植 物生长期为 150 天左右。年降水量为 $365.6 \mathrm{~mm}$, 集中 于6-9月, 占全年降水量的 $80 \%$ 左右。土壤为栗钙 
土。本研究区域主要草原植物为羊草 (Leymus chinensis)、䊁隐子草(Cleistogenes squarrosa)、克氏 针茅(Stipa sareptana var. krylovii)、大针茅(Stipa grandis)、防风(Saposhnikovia divaricata)、冷蒿、瓣 荵唐松草(Thalictrum petaloideum)、阿尔泰狗哇花 (Heterop-appus altaicus)等。

\section{2 材料处理}

2014年6月中旬在采样地挖取生长健壮的冷蒿 植株, 植株高 $20 \mathrm{~cm}$, 栽植于盛有采样地原土的花盆 (直径18 cm, 高20 cm)中, 每盆1从, 每丛10-15小 枝。盆栽植株置于浙江农林大学温室中, 自然光照, 相对湿度为(30 \pm 2$) \%$, 白天气温 $(25 \pm 2){ }^{\circ} \mathrm{C}$, 夜晚 气温 $(20 \pm 2){ }^{\circ} \mathrm{C}$ 。植株生长 20 天后进行试验处理。 选取株高一致、生长良好、无病虫害冷高20盆, 随 机分为 4 组, 以剪刀损伤(剪掉小枝的 $1 / 3$ 长度)和揉 捏方式(用手揉捏小枝上端 $1 / 3$ 处, 将小针叶揉坏) 人 工模拟牲畜对冷蒿枝叶的采食和践踏, 每盆苗处理 $1 / 4$ 枝条为轻度损伤, 处理 $1 / 3$ 枝条为中度损伤, 处 理 $1 / 2$ 枝条为重度损伤, 不做处理为对照。每个损伤 强度处理 5 盆, 每盆为 1 个独立重复。在处理 $6 \mathrm{~h}$ 后分 别对冷蒿枝叶和根系进行取样, 液氮速冻后置于 $-80{ }^{\circ} \mathrm{C}$ 低温冰箱内保存。

\section{3 酚酸提取和含量测定}

酚酸提取参考Brandolini等(2013)的方法并略作 修改。游离酚酸提取: 准确称取 $1 \mathrm{~g}$ 样品, 研磨成粉 末, 加入 $10 \mathrm{~mL}$ 提取液 (甲醇、丙酮、水的体积比为 7:7:6), 不连续振荡提取 $20 \mathrm{~min}, 10000 \times g$ 离心 10 $\min \left(8{ }^{\circ} \mathrm{C}\right)$, 收集上清液; 沉淀用同样方法重复提取 2次, 合并上清液。上清液于 $35{ }^{\circ} \mathrm{C}$ 真空浓缩至大约 $10 \mathrm{~mL}$, 然后加入 $4 \mathrm{~mol} \cdot \mathrm{L}^{-1} \mathrm{NaOH} 10 \mathrm{~mL}$, 在室温和 氮气保护环境下碱解 $4 \mathrm{~h}$, 再用 $6 \mathrm{~mol} \cdot \mathrm{L}^{-1} \mathrm{HCl}$ 调 $\mathrm{pH}$ 值至1.5-2.0, 加入 $20 \mathrm{~mL}$ 乙酸乙酯萃取3次。乙酸乙 酯相提取物中加无水硫酸钠脱水, 过滤。 $30{ }^{\circ} \mathrm{C}$ 真空 浓缩至干, 用色谱纯甲醇定容至 $2 \mathrm{~mL}$, 得到游离酚 酸。测定时经有机微孔滤膜 $(0.45 \mu \mathrm{m})$ 过滤。

结合酚酸提取: 在游离酚酸提取沉淀物中加入 $4 \mathrm{~mol} \cdot \mathrm{L}^{-1} \mathrm{NaOH} 10 \mathrm{~mL}$, 在室温和氮气保护环境下 碱解 $4 \mathrm{~h}$, 再用 $6 \mathrm{~mol} \cdot \mathrm{L}^{-1} \mathrm{HCl}$ 调 $\mathrm{pH}$ 值至1.5-2.0, 加入 $20 \mathrm{~mL}$ 乙酸乙酯萃取 3 次。乙酸乙酯相提取物中加无 水硫酸钠脱水, 过滤。 $30{ }^{\circ} \mathrm{C}$ 真空浓缩至干, 用色谱 纯甲醇定容至 $2 \mathrm{~mL}$, 得到结合酚酸。测定时经有机 微孔滤膜 $(0.45 \mu \mathrm{m})$ 过滤。所有提取过程均需避光。
酚酸含量的测定: 采用 ACQUITY ${ }^{\mathrm{TM}}$ 高效液相 色谱仪(Waters, Milford, USA)测定酚酸含量。色谱 柱为ACQUITY UPLC BEH C $\mathrm{C}_{18}$ 柱 $(1.7 \mu \mathrm{m}, 1.0 \mathrm{~mm} \times$ $100 \mathrm{~mm})$, 柱温为室温, 光电二极管阵列 (PDA)检测 器, 检测波长 $280 \mathrm{~nm}$, 进样量 $1 \mu \mathrm{L}$ 。流动相: $\mathrm{A}$ 为 $0.5 \%$ 乙酸, $\mathrm{B}$ 为乙腈, 流速 $0.1 \mathrm{~mL} \cdot \mathrm{min}^{-1}$ 。洗脱液 $\mathrm{A}$ 的 洗脱梯度为: $0 \mathrm{~min}, 95 \%$; $10 \mathrm{~min}, 90 \%$; $12 \mathrm{~min}, 85 \%$; $15 \mathrm{~min}, 80 \%$; $18 \mathrm{~min}, 77 \%$; $22 \mathrm{~min}, 30 \%$; $28 \mathrm{~min}$, $95 \%$ 。

酚酸标样配制及标准曲线制定: 9种酚酸标样 没食子酸、原儿茶酸、绿原酸、邻苯二酚、咖 啡酸、丁香酸、对香豆酸、阿魏酸、肉桂酸均购自 Sigma公司。分别称取酚酸标准样品 $1 \mathrm{mg}$, 用色谱纯 甲醇定容至5 mL配成酚酸混合标样母液(严善春等, 2010)。将其母液稀释10倍、20倍、50倍、100倍、 200倍, 配成一系列浓度的混合标样, 根据上述液相 色谱条件上样, 得到标准溶液色谱分离结果, 标样 分离效果良好。然后以各种酚酸峰面积为纵坐标, 酚酸浓度为横坐标进行线性回归, 得到回归方程。 标准物没食子酸、原儿茶酸、绿原酸、邻苯二酚、 咖啡酸、丁香酸、对香豆酸、阿魏酸、肉桂酸的相 关系数分别为 0.993 3、0.989 4、0.987 4、0.994 7、 0.993 4、0.992 1、0.987 2、0.992 6、0.986 2, 表明 标准物峰面积与浓度之间具有极显著线性相关关 系。根据酚酸标准品的保留时间及其在 $280 \mathrm{~nm}$ 的紫 外吸收光谱对样品中的酚酸定性, 用Waters色谱工 作站测定纯度后, 依据外标曲线计算酚酸的含量 $\left(\mu \mathrm{g} \cdot \mathrm{g}^{-1}\right.$ 鲜质量)。

\section{4 酶液提取}

PAL和PPO酶液提取: 称取 $0.2 \mathrm{~g}$ 冷冻样品, 加 5 $\mathrm{mL}$ 硼酸缓冲液 $\left(100 \mathrm{mmol} \cdot \mathrm{L}^{-1}, \mathrm{pH}\right.$ 8.0)冰浴条件下研 磨至匀浆, 在 $10000 \times g$ 离心 $20 \mathrm{~min}\left(4{ }^{\circ} \mathrm{C}\right)$, 上清液 用于PPO活性和PAL活性测定。

SOD、POD和CAT酶液提取: 称取 $0.2 \mathrm{~g}$ 冷冻样 品液氮研磨, 加 $5 \mathrm{~mL}$ 磷酸缓冲溶液 $\left(50 \mathrm{mmol} \cdot \mathrm{L}^{-1}\right.$, $\mathrm{pH}$ 7.8)匀浆, $10000 \times g$ 离心 $10 \min \left(4{ }^{\circ} \mathrm{C}\right)$ 。上清液 用于SOD、POD和CAT活性测定和蛋白质含量测定。

\section{5 酶活性测定}

PPO活性测定参考Tan和Harris (1995)的方法并 略作修改。在 $2.9 \mathrm{~mL}$ 反应液 $\left(0.05 \mathrm{~mol} \cdot \mathrm{L}^{-1}\right.$ 磷酸缓冲液 $\mathrm{pH} 7.4$, 含 $0.02 \mathrm{~mol} \cdot \mathrm{L}^{-1}$ 邻苯二酚 $)$ 中加入 $100 \mu \mathrm{L}$ 酶提 取液, 混匀后于 $420 \mathrm{~nm}$ 处测定 $2 \mathrm{~min}$ 内吸光度值的 
变化。以每分钟吸光度值变化 0.01 表示 1 个酶活力单 位, PPO活性用 $\mathrm{U} \cdot \mathrm{g}^{-1} \mathrm{Pro} \cdot \mathrm{min}^{-1}$ 表示。

PAL活性测定参考Jiang和Joyce (2003)的方法 并略作修改。在 $2.9 \mathrm{~mL}$ 反应液 $\left(0.1 \mathrm{~mol} \cdot \mathrm{L}^{-1}\right.$ 硼酸缓冲 液 $\mathrm{pH}$ 8.0, 含 $3 \mathrm{mmol} \cdot \mathrm{L}^{-1} \mathrm{~L}$-苯丙氨酸)中加入 $100 \mu \mathrm{L}$ 酶液, 混匀后于 $290 \mathrm{~nm}$ 处测定吸光度值的变化, 同 样条件下, 将另外一个 $3 \mathrm{~mL}$ 反应体系在 $30{ }^{\circ} \mathrm{C}$ 保温 1 $\mathrm{h}$ 后于 $290 \mathrm{~nm}$ 测定吸光度值。 $\mathrm{PAL}$ 活性用 $\mathrm{U} \cdot \mathrm{g}^{-1}$ Pro· $\min ^{-1}$ 表示。

SOD活性测定参照Giannopolitis和Ries (1977) 的方法; CAT 和 POD 活性测定参照 Fu 和 Huang (2001)的方法。

\section{6 蛋白质含量测定}

可溶性蛋白质含量测定参照Bradford (1976)的 方法。

\section{7 数据处理}

所有数据均为 5 次重复的平均值 \pm 标准误差。利 用Origin 8进行统计分析和作图, 统计方法采用单 因素方差分析进行检验, 并进行Fisher LSD多重比 较 $(p<0.05)$ 。

\section{2 结果和分析}

\section{1 机械损伤对冷蒿体内酚酸含量的影响}

轻度机械损伤处理冷蒿枝叶后, 游离没食子酸 和原儿茶酸含量显著增加, 绿原酸和邻苯二酚含量 显著下降 $(p<0.05)$, 但是总游离酚酸含量与对照相 比差异不显著 $(p>0.05)$ (表1), 说明该机械损伤程度 对枝叶游离酚酸含量未达到诱导阈限。苯甲酸型中 的没食子酸和原儿茶酸可以形成单宁, 是抗虫活性 的物质, 随着损伤强度的加强, 没食子酸和原儿茶 酸显著增加, 不断积累, 重度损伤处理比对照分别 增加了 $280.6 \%$ 和 $215.7 \%(p<0.05)$, 达到峰值; 苯丙 烯酸型酚酸是合成木质素的中间产物, 能增加植物 细胞壁的强度, 咖啡酸、丁香酸、阿魏酸和肉桂酸 含量随着损伤的加强而增加, 中度损伤处理比对照 分别增加了 $150.4 \% 、 93.5 \%$ 、154.4\%和121.7\% $(p<$ 0.05), 随后含量下降; 绿原酸和邻苯二酚可以被 PPO氧化成醌类, 重度损伤处理比对照分别下降了 91.1\%和69.3\% ( $p<0.05)$, 其含量随着损伤的加强 而下降, 随后达到最低值。从总游离酚酸含量看, 随 着枝叶被损伤, 其含量不断增加, 中度和重度损伤 比对照分别增加了 $61.4 \%$ 和 $66.5 \%$, 呈显著增加, 说
明中度和重度损伤处理已经达到了诱导阈值。

从结合酚酸来看, 轻度机械损伤处理冷蒿枝叶 后，没食子酸、原儿茶酸、绿原酸、咖啡酸、丁香 酸、对香豆酸、阿魏酸和总结合态酚酸含量均下降, 且与对照相比差异均不显著 $(p>0.05)$, 说明该损伤 程度对枝叶中结合酚酸含量未达到诱导阈值。随着 机械损伤强度增加, 苯甲酸型中的原儿茶酸和绿原 酸含量显著增加, 重度损伤处理比对照分别增加了 $57.2 \%$ 和 $11.5 \%$; 苯丙烯酸型中的对香豆酸和阿魏酸 含量增加显著, 重度损伤处理后比对照分别增加了 $32.0 \%$ 和 $34.2 \%$ 。从总结合酚酸看，中度和重度损伤 结合酚酸比对照分别增加了 $26.8 \%$ 和 $18.6 \%(p<$ 0.05), 说明中度和重度损伤处理已经达到了诱导阈 值。结果表明, 冷蒿枝叶中游离酚酸较结合酚酸对 机械损伤的响应更为明显, 其含量变化与损伤强度 密切相关，中度和重度损伤处理比对照显著增加。

冷蒿枝叶经不同强度机械损伤处理后，根系中 9 种游离酚酸含量发生显著变化(表2)。轻度机械损 伤处理, 根系中游离酚酸含量显著增加的有原儿茶 酸、咖啡酸、对香豆酸、肉桂酸和总酚酸; 随着损 伤的加强, 根系中9种游离酚酸含量都显著增加, 特 别是重度损伤，酚酸含量较对照均增加 $80 \%$ 以上， 尤其是原儿茶酸含量增加了 6.2 倍; 而总酚酸含量, 中度和重度损伤比对照分别增加了 $161.3 \%$ 和 $195.3 \%$ 。说明轻度机械损伤处理已经达到了诱导阈 值, 根系中游离酚酸积累比枝叶迅速, 相同诱导强 度下根系中总酚酸含量显著高于枝叶。

在根系中，对照组结合态丁香酸、对香豆酸、 阿魏酸和总酚酸高于枝叶, 其他6种酚酸含量均低 于枝叶中, 表明根系中存在大量结合态酚酸。根系 中结合态酚酸含量随着机械损伤明显减少, 轻度、 中度和重度损伤后没食子酸、绿原酸、邻苯二酚、 对香豆酸、阿魏酸、肉桂酸和总酚酸含量减少 $35.6 \%-76.1 \%$ ，显著低于对照，说明轻度损伤处理 已经能够达到诱导阈值。根系中结合态酚酸含量减 少, 枝叶中结合态酚酸含量增加。

\section{2 机械损伤对冷蒿PPO和PAL活性的影响}

PAL 是苯丙烷酸代谢途径上的调控酶, 参与酚 酸和木质素的生物合成, 增加植物的抗逆性。不同 机械损伤冷蒿体内PAL活性变化见图1。轻度、中度 和重度处理，枝叶PAL活性比对照分别升高了 2.88 倍、3.88倍和4.92倍 $(p<0.05)$, 表明轻度损伤处理枝 

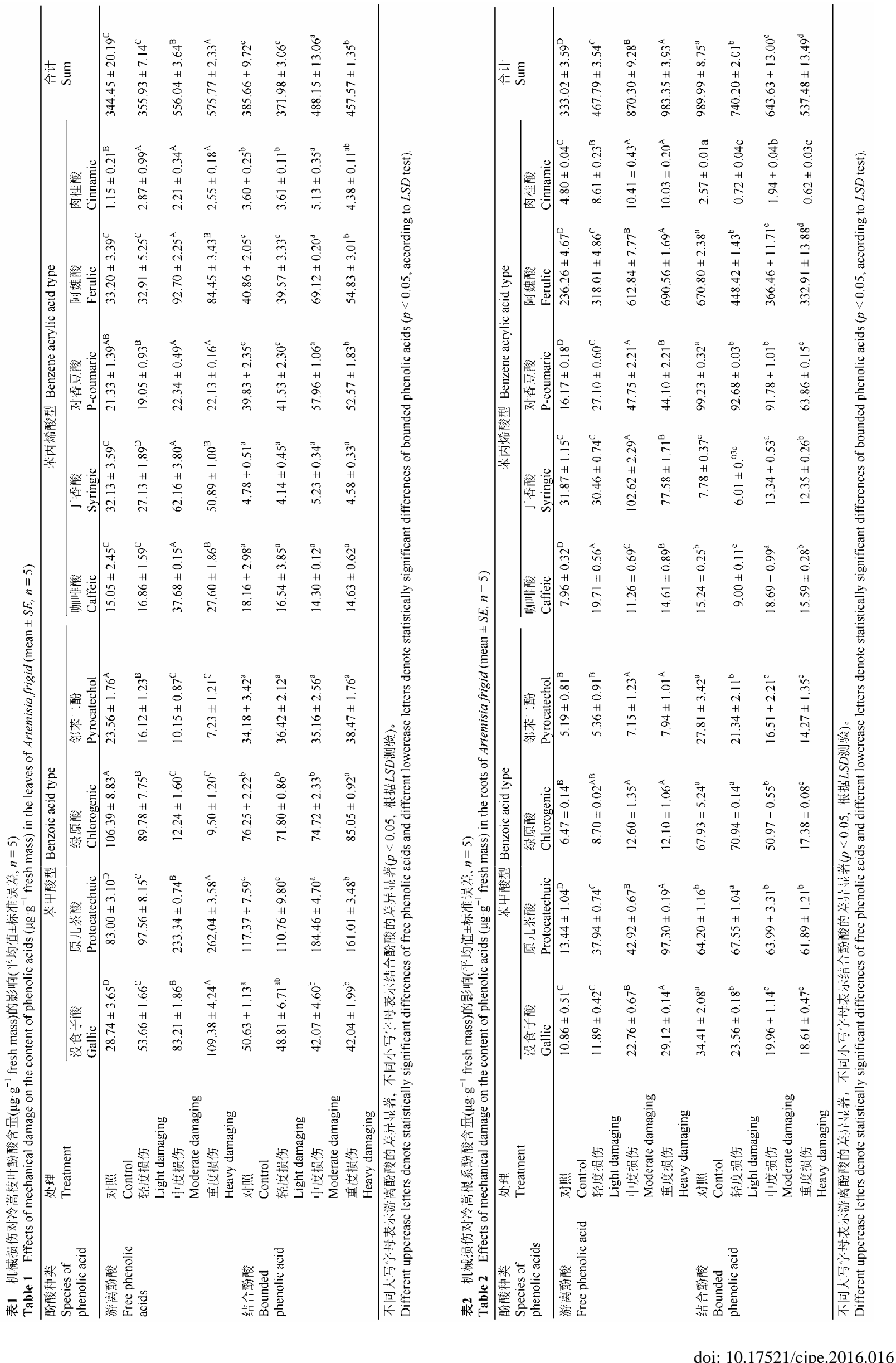

doi: 10.17521/cjpe.2016.0161 


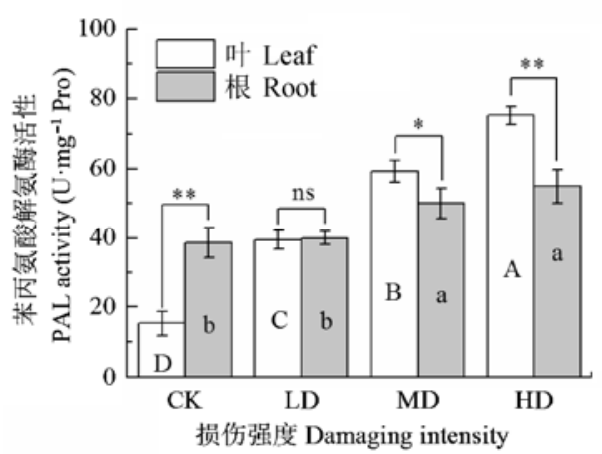

图1 机械损伤对冷蒿苯丙氨酸氨裂合酶活性的影响(平均 值土标准误差, $n=5)$ 。不同大写字母表示冷蒿枝叶的差异显 著, 不同小写字母表示根系的差异显著 $(p<0.05$, 根据 $L S D$ 测验)。 ${ }^{*}, p<0.05 ;^{* *}, p<0.01$ ns, 不显著。CK, 对照; LD 为轻度损伤; $M D$ 为中度损伤; HD为重度损伤。

Fig. 1 Effect of mechanical damage on the activity of phenylalanine ammonia-lyase (PAL) in Artemisia frigid (mean $\pm S E, n=5$ ). Different uppercase letters indicate significant differences of leaves and different lowercase letters denote statistically significant differences of roots from Artemisia frigida ( $p<0.05$, according to $L S D$ test). ${ }^{*}, p<0.05$; $^{* *}, p<0.01$; ns, non-significant. CK, control; LD, light damaging; MD, moderate damaging; $\mathrm{HD}$, heavy damaging.

叶, 已经能够达到诱导阈值, 激活枝叶 PAL活性, 使其迅速增加; 而根系PAL活性在中度损伤后, 才 显著增加, 表明中度损伤才能够达到根系PAL活性 诱导阈值。对照组枝叶PAL活性低于根系, 损伤处 理后, 枝叶中PAL活性增加比根系中迅速, 表明枝 叶中PAL活性对刺激响应迅速, 而根系中响应迟 缓。机械损伤能够促进枝叶中酚酸的合成。

$\mathrm{PPO}$ 可以把酚酸氧化成醌类的物质, 防止病原 菌感染。图2显示了不同损伤程度对冷蒿体内PPO活 性的影响。轻度、中度和重度处理下, 枝叶中PPO活 性比对照分别升高了 41.7\%、103.7\%和197.8\%（ $p<$ 0.05), 而根系PPO活性分别升高了 7.0\%、99.3\%和 $163.9 \%$, 表明轻度损伤处理冷蒿枝叶, 已经能够达 到诱导阈值, 激活枝叶和根系中PPO, 使其活性迅速 增加。各处理中枝叶PPO活性均高于根系, 且差异极 显著, 表明枝叶 $\mathrm{PPO}$ 氧化酚酸的能力强于根系, 形成 的醌类物质含量高于根系, 增强了枝叶的保护能力。

\section{3 机械损伤对冷蒿抗氧化酶活性的影响}

随着机械损伤强度的增加, SOD、CAT和POD 活性逐渐增强(图3), 轻度、中度和重度损伤处理, 枝叶中SOD活性比对照分别增加了1.96倍、2.36倍和 4.98 倍 $(p<0.05)$; 中度和重度损伤, 根系中SOD活 性比对照分别增加了 $68.3 \%$ 和 $147.2 \%(p<0.05)$

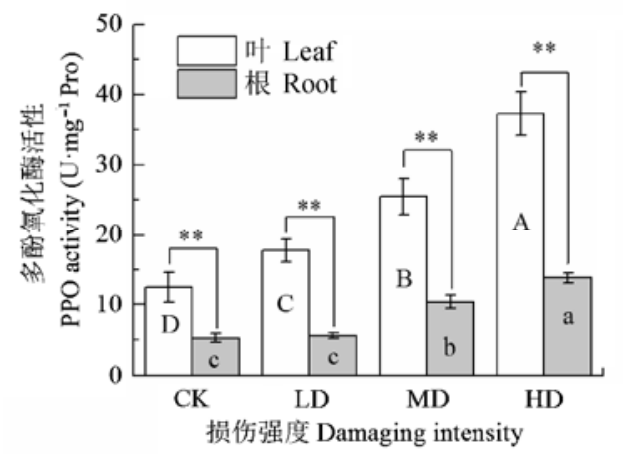

图2 机械损伤对冷蒿多酚氧化酶活性的影响(平均值土标准 误差, $n=5)$ 。不同大写字母表示冷蒿枝叶的差异显著, 不同 小写字母表示根系的差异显著 $(p<0.05$, 根据 LSD测验)。 $* p$ $<0.05$; **, $p<0.01$ 。ns, 不显著。CK, 对照; LD为轻度损伤; $\mathrm{MD}$ 为中度损伤; HD为重度损伤。

Fig. 2 Effect of mechanical damage on the activity of polyphenol oxidase (PPO) in Artemisia frigid (mean $\pm S E, n=5$ ). Different uppercase letters indicate significant differences of leaves and different lowercase letters denote statistically significant differences of roots from Artemisia frigida $(p<0.05$, according to $L S D$ test). ${ }^{*}, p<0.05 ;{ }^{* *}, p<0.01$; ns, non-significant. CK, control; LD, light damaging; MD, moderate damaging; $\mathrm{HD}$, heavy damaging.

(图3A)。表明轻度损伤能够诱导枝叶SOD活性迅速 增加, 达到诱导阈值; 中度损伤根系达到诱导阈 值。各处理中枝叶SOD活性显著高于根系, 表明枝 叶SOD活性对机械损伤的响应明显高于根系, 消除 $\mathrm{O}_{2}{ }^{\top}$ 的能力很强。

中度和重度损伤后, 枝叶和根系CAT活性与对 照相比显著增强(图3B), 枝叶中比对照分别增加了 $35.4 \%$ 和 $147 . .6 \%(p<0.05)$, 根系中比对照分别增加 了 $63.7 \%$ 和 $173.3 \%(p<0.05)$, 表明中度损伤处理能 够达到诱导阈值; 枝叶CAT活性高于根系, 枝叶消 除 $\mathrm{H}_{2} \mathrm{O}_{2}$ 能力强于根系。

轻度、中度和重度处理后, 枝叶中POD活性分 别比对照增加了1.62倍、2.51倍和3.18倍 $(p<0.05)$; 根系分别比对照增加1.22倍、2.15倍和 2.40 倍 $(p<$ 0.05 ) (图3C), 表明轻度损伤处理已经能够达到诱导 阈值, 枝叶中POD活性高于根系。说明枝叶POD活 性对机械损伤的响应高于根系, 枝叶能够快速有效 地消除损伤细胞内多余的 $\mathrm{H}_{2} \mathrm{O}_{2}$ 。

总之, 机械损伤能够诱导冷蒿体内SOD、CAT 和POD活性显著升高, 3种防御酶协同作用, 共同达 到清除活性氧的目的; PAL活性显著升高, 诱导大 量酚酸形成, PPO活性升高, 诱导大量醌类物质形 成, 增加抵抗能力; 而PAL和PPO活性响应机械损 


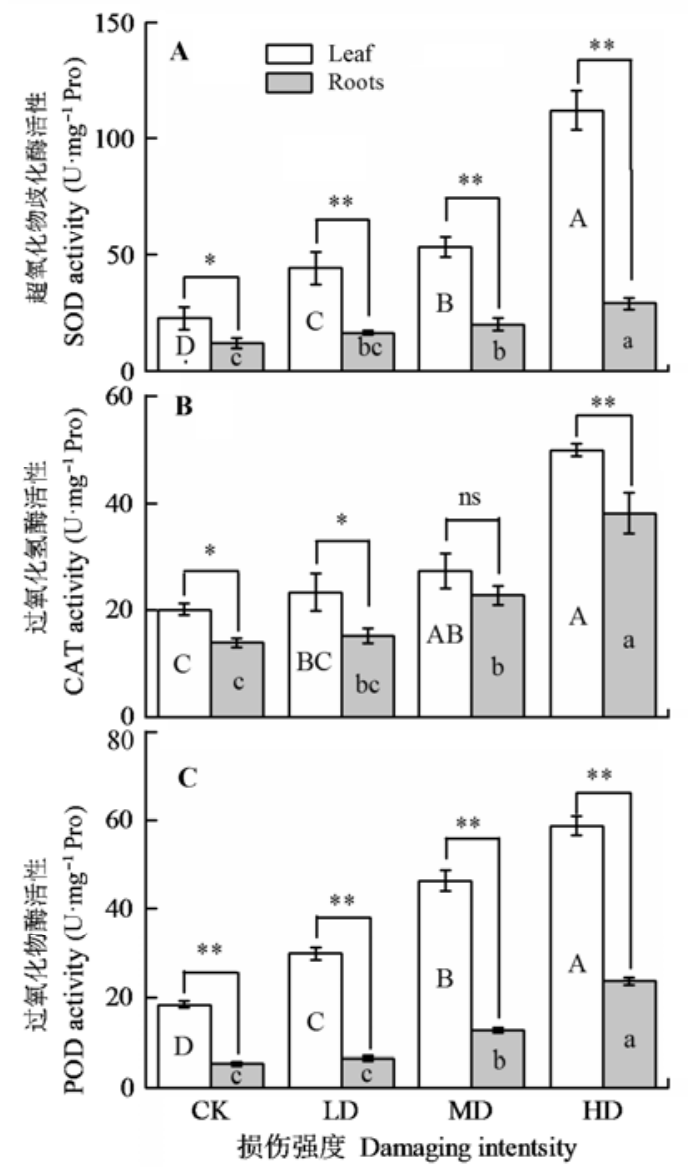

图3 机械损伤对冷藁抗氧化酶活性的影响(平均值土标准误 差, $n=5$ )。不同大写字母表示冷蒿枝叶的差异显著, 不同小 写字母表示根系的差异显著 $(p<0.05$, 根据 $L S D$ 测验 $)$ 。 ${ }^{*}, p<$ $0.05 ;{ }^{* *}, p<0.01$ 。ns, 不显著。CK, 对照; LD为轻度损伤; MD 为中度损伤; $\mathrm{HD}$ 为重度损伤。

Fig. 3 Effect of mechanical damage on activity of antioxidant enzyme in Artemisia frigid (mean $\pm S E, n=5$ ). Different uppercase letters indicate significant differences of leaves and different lowercase letters denote statistically significant differences of roots from Artemisia frigida $(p<0.05$, according to $L S D$ test). ${ }^{*}, p<0.05 ;{ }^{* *}, p<0.01$; ns, non-significant. CK, control; LD, light damaging; MD, moderate damaging; HD, heavy damaging.

伤的诱导作用比防御每(SOD、CAT和POD)敏感, 在 机械损伤诱导下PAL和PPO活性提高的幅度较大。 枝叶的防御能力明显迅速和强于根系。

\section{4 冷蒿体内酚酸含量与酶活性的相关性分析}

为进一步研究冷蒿体内酚酸种类和含量与抗机 械损伤强度的关系, 对 9 种酚酸和总酚酸含量与 PPO、PAL活性间进行相关性分析。由表3可见, 枝 叶中游离态没食子酸、原儿茶酸、酚酸总量和阿魏 酸、咖啡酸、肉桂酸含量与PAL酶活性有极显著正 相关和显著正相关关系, 表明PAL酶活性增加, 促 进这几种酚酸的合成, 导致含量积累, PAL酶有明
显的贡献; 绿原酸和邻苯二酚含量与PPO酶活性呈 极显著负相关关系, 表明 PPO酶活性的增加促进绿 原酸和邻苯二酚转化成醌类物质, PPO有显著贡献。 枝叶中结合态原儿茶酸、肉桂酸和绿原酸、邻苯二 酚、阿魏酸、对香豆酸、丁香酸、酚酸总量与PAL 酶活性有显著正相关和正相关关系, 表明PAL酶活 性的增加, 促进这几种结合酚酸的合成, 导致含量 积累, PAL酶有贡献; 绿原酸、邻苯二酚和对香豆酸 与 PPO酶活性呈显著正相关关系, 没食子酸与 PPO 和PAL酶活性呈负相关关系。从表4可以看出, 冷蒿 根系游离态原儿茶酸和没食子酸、阿魏酸和酚酸总 量与PAL酶活性呈极显著正相关和显著正相关关 系, 咖啡酸、丁香酸、对香豆酸、肉桂酸与PAL酶 活性有正相关关系, 表明PAL酶活性的增加促进这 几种酚酸的合成, 导致其含量积累, PAL酶有明显 贡献; 没食子酸、原儿茶酸、绿原酸、邻苯二酚、 对香豆酸、阿魏酸、肉桂酸和酚酸总量与PPO酶活 性呈极显著正相关关系, 丁香酸与 PPO酶活性呈显 著正相关关系, 表明这几种酚酸含量增加, 在细胞 内积累。结合态的7种酚酸与PAL和PPO活性呈极显 著负相关和显著负相关关系, 表明这几种酚酸进行 了分解, 含量下降。

\section{3 讨论}

植物在长期自然选择进化与环境相互作用过程 中形成了整套的防御机制, 以主动适应生存环境的 变化, 如产生形态、器官和组织结构的防御(即物理 防御) 以及通过增加酚类物质含量和防御酶活性的 生物化学防御(即化学防御)。酚酸是植物化学防御 的重要次生代谢物质, 机械损伤、昆虫取食和病原 侵染均可以诱导植物体内酚酸的合成, 增加植物的 抗性 (Dixon \& Paiva，1995; Dicke et al., 2003; Kestring et al., 2009)。植物体内具有防御作用的酚 酸种类繁多、含量各异、作用方式也不同。落叶松 (Larix gmelinii)针叶在机械损伤后, 可以诱导苯甲 酸、咖啡酸、苯乙酸、香草酸、丁香酸和没食子酸 含量迅速增加(Campos-Vargas \& Saltveit, 2002; 胡 增辉等, 2009; 严善春等, 2010)。在本研究结果中, 冷蒿枝叶机械损伤后, 诱导体内游离态没食子酸、 原儿茶酸、咖啡酸、丁香酸、阿魏酸和结合态原儿 茶酸、对香豆酸、阿魏酸含量迅速增加, 说明这几 种酚酸可能是冷蒿枝叶的重要防御物质。 
表3 冷蒿枝叶酚酸含量与酶活性之间相关性分析

Table 3 Correlation analysis between the content of phenolic acids and related enzyme activities in the leaves of Artemisia frigid

\begin{tabular}{|c|c|c|c|c|c|c|c|c|c|c|c|}
\hline & $\begin{array}{l}\text { 酶 } \\
\text { Enzyme }\end{array}$ & $\begin{array}{l}\text { 没食子酸 } \\
\text { Gallic }\end{array}$ & $\begin{array}{c}\text { 原儿茶酸 } \\
\text { Protocatechuic }\end{array}$ & $\begin{array}{c}\text { 绿原酸 } \\
\text { Chlorogenic }\end{array}$ & $\begin{array}{c}\text { 邻苯二酚 } \\
\text { Pyrocatechol }\end{array}$ & $\begin{array}{l}\text { 咖啡酸 } \\
\text { Caffeic }\end{array}$ & $\begin{array}{l}\text { 丁香酸 } \\
\text { Syringic }\end{array}$ & $\begin{array}{c}\text { 对香豆酸 } \\
\text { P-coumaric }\end{array}$ & $\begin{array}{l}\text { 阿魏酸 } \\
\text { Ferulic }\end{array}$ & $\begin{array}{c}\text { 肉桂酸 } \\
\text { Cinnamic }\end{array}$ & $\begin{array}{l}\text { 合计 } \\
\text { Sum }\end{array}$ \\
\hline 游离酚酸 & PPO & $0.968^{* *}$ & $0.861^{* *}$ & $-0.835^{* * 4}$ & $-0.871^{* *}$ & 0.548 & 0.556 & -0.194 & $0.723^{*}$ & 0.559 & $0.831^{* *}$ \\
\hline Free phenolic acid & PAL & $0.859^{* *}$ & $0.763^{* *}$ & $-0.785^{* *}$ & $-0.793^{* *}$ & $0.641^{*}$ & 0.531 & -0.069 & $0.690^{*}$ & $0.688^{*}$ & $0.752^{* *}$ \\
\hline 结合酚酸 & PPO & $-0.635^{*}$ & 0.564 & $0.670^{*}$ & $0.742^{*}$ & -0.493 & -0.050 & $0.579^{*}$ & 0.487 & 0.480 & 0.559 \\
\hline Bounded phenolic acid & PAL & $-0.646^{*}$ & $0.576^{*}$ & 0.413 & 0.542 & -0.489 & 0.126 & 0.572 & 0.551 & $0.617^{*}$ & 0.558 \\
\hline
\end{tabular}

PAL，苯丙氨酸氨裂合酶; PPO, 多酚氧化酶。

PAL, phenylalanine ammonia-lyase; PPO, polyphenol oxidase. *, $p<0.05$; **, $p<0.01$ 。

表4 冷蒿根系酚酸含量与酶活性之间相关性分析

Table 4 Correlation analysis between the content of phenolic acids and related enzyme activities in the roots of Artemisia frigid

\begin{tabular}{|c|c|c|c|c|c|c|c|c|c|c|c|}
\hline & $\begin{array}{l}\text { 酶 } \\
\text { Enzyme }\end{array}$ & $\begin{array}{l}\text { 没食子酸 } \\
\text { Gallic }\end{array}$ & $\begin{array}{l}\text { 原儿茶酸 } \\
\text { Protocatechuic }\end{array}$ & $\begin{array}{l}\text { 绿原酸 } \\
\text { Chlorogenic }\end{array}$ & $\begin{array}{l}\text { 邻苯二酚 } \\
\text { Pyrocatechol }\end{array}$ & $\begin{array}{l}\text { 咖啡酸 } \\
\text { Caffeic }\end{array}$ & $\begin{array}{l}\text { 丁香酸 } \\
\text { Syringic }\end{array}$ & $\begin{array}{l}\text { 对香豆酸 } \\
\text { P-coumaric }\end{array}$ & $\begin{array}{l}\text { 阿魏酸 } \\
\text { Ferulic }\end{array}$ & $\begin{array}{l}\text { 肉桂酸 } \\
\text { Cinnamic }\end{array}$ & $\begin{array}{l}\text { 合计 } \\
\text { Sum }\end{array}$ \\
\hline 游离酚酸 & PPO & $0.974^{* *}$ & $0.953^{* *}$ & $0.782^{* *}$ & $0.861^{* *}$ & 0.113 & $0.696^{*}$ & $0.797^{* *}$ & $0.933^{* *}$ & $0.711^{* *}$ & $0.933^{* *}$ \\
\hline Free phenolic acids & PAL & $0.678^{*}$ & $0.774^{* *}$ & 0.478 & 0.511 & 0.254 & 0.346 & 0.483 & $0.618^{*}$ & 0.473 & $0.622^{*}$ \\
\hline 结合酚酸 & PPO & $-0.757^{* *}$ & $-0.581^{*}$ & $-0.977^{* *}$ & $-0.912^{* *}$ & 0.419 & $0.772^{* *}$ & $-0.938^{* *}$ & $-0.611^{*}$ & -0.529 & $-0.709^{* *}$ \\
\hline Bounded phenolic acids & PAL & -0.540 & -0.465 & $-0.725^{* *}$ & -0.561 & 0.106 & 0.425 & $-0.789^{* *}$ & $-0.635^{*}$ & -0.544 & $-0.689^{*}$ \\
\hline
\end{tabular}

PAL, 苯丙氨酸氨裂合酶; PPO, 多酚氧化酶。

PAL, phenylalanine ammonia-lyase; PPO, polyphenol oxidase. ${ }^{*}, p<0.05 ;{ }^{* *}, p<0.01$ 。

酚酸分为游离形式和结合形式两类, 游离酚酸 在细胞中的含量低于结合态, 其结构较简单, 咜存 在植物细胞的液泡中, 直接参加细胞内代谢, 有较 强的抗氧化能力, 也可以合成木质素等物质。结合 酚酸是以酯键、糖苷键、醚键等形式与细胞内其他 物质相结合为储藏形式(Robbins, 2003; 徐贵华等, 2008), 比较稳定, 能积累达到很高含量, 水稻 (Oryza sativa)、玉米(Zea mays)和大麦(Hordeum vulgare) 中结合酚酸含量高于游离酚酸(Adom \& Liu, 2002)。植物体内游离酚酸和结合酚酸可以相互 转化, 两者处于动态平衡(林开敏等, 2010)。本研究 结果表明, 机械损伤后冷蒿枝叶中游离酚酸总量和 结合酚酸总量都显著增加, 最终游离酚酸总量显著 高于结合酚酸总量。其中, 可形成单宁的没食子酸、 原儿茶酸含量显著增高(表1), 增加了冷高枝叶的苦 涩感, 可形成木质素的丁香酸、对香豆酸、阿魏酸、 肉桂酸含量增高, 增加了枝叶的硬度。表明机械损 伤诱导游离酚酸和结合酚酸迅速合成, 为木质素和 单宁的合成提供原料, 增加植物的抵抗能力。根系 试验表明, 随着机械损伤的加强, 原有的酚酸平衡 体系被打乱, 建立了新的平衡体系, 游离酚酸含量 显著升高, 结合酚酸显著下降(表2)。我们推测, 当 植物受到损伤后, 根系中参加苯丙烷酸代谢的底 物、能量和酶是有限的, 在短时间内只能形成一部 分游离酚酸, 而通过部分结合酚酸转化成游离酚酸,
提高游离酚酸的含量, 降低结合酚酸含量。表明酚 酸的存在形式在应激状态下会发生转变, 结合态向 着游离态转化, 以增加根系内的应激物质。

植物体地上和地下是统一的整体, 有着极密切 的生长关系, 地上和地下相互制约与协调。植物地 上部分进行光合作用制造碳水化合物, 供给根部, 而根部吸收水分和矿质供给地上部分。研究表明植 物被刈割后, 叶面积大幅度降低, 其净光合速率也 下降, 由于地上部分的营养体减少, 地下资源过盛, 促使植物地上积累更多的碳水化合物, 补充形成应 激反应所需要的原料和能量(王静等, 2003; Zhao \& Baoyin, 2014)。因此通过增加地上部分可溶性碳水 化合物进行调节。在苯丙烷酸代谢途径中可溶性碳 水化合物是原料, 可以促进地上部分产生大量的酚 酸。因此, 机械损伤后, 冷高枝叶中游离酚酸和结合 酚酸作为应激物质, 含量均显著增加。由于地上部 分向地下部分输送可溶性碳水化合物减少, 根系缺 乏合成酚酸的原料, 只有通过降解结合酚酸的方式, 才能大量增加游离酚酸。表明枝叶中游离酚酸和结 合酚酸作为应激物质在不断地进行合成, 而根系中 由于资源有限, 只能降解结合酚酸来增加游离酚酸, 以增加冷蒿的抗性，对地上部分的损伤做出响应。

诸多研究表明, 游离态酚酸都具有很强的抗氧 化性能，能有效地清除自由基，抑制膜脂过氧化和 清除重金属, 植物抗氧化活性与体内酚酸含量有显 
著的相关关系(Matkowski, 2006; Brandolini et al., 2013; 刘再等, 2014)。植物产生防御反应的特征之 一, 是酚酸含量显著升高, 植物受到机械损伤、昆虫 取食等均能诱导体内酚酸含量迅速增加, 以增加植 物的抵抗能力(Nicholson \& Hammerschmidt, 1992; Campos \& Saltveit, 2002; Kováčik et al., 2010)。进一 步研究发现, 黄肉马铃薯(Solanum tuberosum)抗氧 化能力的主要贡献者是绿原酸、没食子酸、咖啡酸 和儿茶素, 而紫肉马铃薯的主要贡献者是花青素 (Lachman et al., 2009; Meng et al., 2012)。苯丙烯酸 类酚酸的抗氧化活性高于羟基苯甲酸类, 可能是由 于苯丙烯酸类中存在 $\mathrm{CH}=\mathrm{CH}-\mathrm{COOH}$, 而羟基苯 甲酸类存在 $\mathrm{COOH}$, 前者表现出较强的供氢能力和 清除自由基的能力。因此, 咖啡酸、阿魏酸和对香 豆酸的抗氧化活性高于原儿茶酸、香草酸和对羟基 苯甲酸(Meng et al., 2012)。本研究显示, 机械损伤后 冷蒿枝叶和根系中羟基苯甲酸类和苯丙烯酸类酚酸 都显著增加, 表明冷蒿体内抗氧化活性很强。

植物通过调控次生代谢产物进行化学防御是一 种有效的策略, 植物次生代谢途径关键酶的活性是 其防御体系形成的重要前提(Puthoff \& Smigocki, 2007)。在高等植物中PAL和PPO是普遍存在的两种 重要酶, PAL 是苯丙烷类代谢的关键酶和限速酶, 调控苯丙氨酸形成阿魏酸、肉桂酸、咖啡酸等的合 成, 是细胞内与木质素生成有关的防御酶(Baque et al., 2010); 很多植物受到机械损伤和昆虫咬食后, PAL活力升高(王琪等, 2012), PAL可以被许多环境 胁迫如伤害、UV、乙烯、激发子等激活(WinkelShirley, 1999; Jiang \& Joyce, 2003 )。本研究结果显 示, 冷蒿机械损伤后, 枝叶中PAL活力显著增加(图 1), 同时, 可以形成木质素(阿魏酸、肉桂酸、咖啡 酸), 形成单宁(没食子酸、原儿茶酸)的酚酸含量也 显著增加, 两者具有显著正相关和极显著正相关关 系(表3)。表明PAL活性增加, 能够诱导冷蒿体内形 成大量的游离态和结合态酚酸, 参与木质素的合成, 增加植物抗机械损伤能力(根系中的变化与枝叶相 同)。PPO是酚类物质氧化的关键酶, 当植物受到损 伤后, PPO催化酚酸氧化形成醌, 积累在损伤部位, 防止植物感染, 增强植物的抵抗能力(Haruta et al., 2001; Paul \& Gooding, 2001; Koussevitzky et al., 2004)。本研究发现, 冷蒿枝叶损伤后, 能够诱导枝 叶PPO活性上升, 同时游离绿原酸和邻苯二酚含量
显著降低(表1), 两者有负相关关系(表3)。表明枝叶 中游离绿原酸和邻苯二酚要形成大量的醌类物质, 防止微生物感染; 由于根系未受到损伤, 不需要形 成大量醌类保护物质, PPO活性显著低于枝叶。该结 论与前人的研究结果一致。

机械损伤作为一种非生物胁迫, 对冷高产生伤 害, 同时使植株产生大量的活性氧(ROS), 高浓度 ROS可以加强膜脂过氧化作用, 使细胞膜、叶绿体、 蛋白质、核酸、脂类等被氧化损伤, 对细胞造成伤 害(刘再等, 2014)。植物具有高效清除ROS的机制, 降低ROS对细胞的伤害(Nordberg \& Arner, 2001; Sharma et al., 2012)。SOD在对抗活性氧时起第一道 防线的作用, 可催化 $\mathrm{O}_{2}{ }^{-}$生成 $\mathrm{H}_{2} \mathrm{O}_{2}$ 和 $\mathrm{O}_{2}$; CAT则具有 分解 $\mathrm{H}_{2} \mathrm{O}_{2}$ 的作用; POD活性的增加, 可减少细胞内 过氧化物的积累(Gill \& Tuteja, 2010)。本研究表明, 随着机械损伤强度的增加, 冷蒿体内SOD、POD、 CAT酶活性逐渐增强, 3种酶协同作用, 增强了清除 ROS的能力, 减少了自由基对细胞的伤害, 对冷蒿 起到一定的保护作用, 进而表现出对机械损伤危害 具有抗性。该结论与前人的研究结果一致。

在自然生长状态下, 冷蒿抗刚割和损伤的能力 很强, 特别是牛羊啃食和践踏后, 促进其萌菜、生根 和盘状根系不断扩大, 许多研究表明, 适度刈割有 利于冷蒿体内碳水化合物、生物量积累和促进再生 生长能力(王静等, 2003)。因此, 在放牧过程中, 只 有适度利用草地资源, 才能使草场可持续利用和发 展, 使退化草原进行恢复和演替。总之, 冷蒿在受到 机械损伤后, 体内的应激防御反应系统被激活, 迅 速诱导酚类代谢相关酶PPO、PAL和抗氧化酶活性 升高, 调节酚酸的表达与积累, 使其抗性增强。冷蒿 对不同强度机械损伤的适应策略不同, 轻度损伤下, 通过增加抗氧化酶活性抵御损伤; 而在中度和重度 损伤处理后, 枝叶通过增加体内抗氧化物质酚酸 (游离态和结合态)含量、醌类物质和抗氧化酶系统 活性共同作用, 抵御机械损伤的危害; 而根系中通 过结合态酚酸转化成游离态, 与抗氧化酶系统共同 抵御损伤。因此, 酚酸和抗氧化酶活性作为冷高应 对放牧防御系统中重要的组成部分, 两者协同作用, 提高冷蒿的抗机械损伤能力, 增强其耐牧生存 能力。

基金项目国家自然科学基金(31270756和 31470704)、国家重点基础研究发展计划(973计划) 
(2014CB138805) 和国家科技支撑计划项目 (2011BAC07B01)。

\section{参考文献}

Adom KK, Liu RH (2002). Antioxidant activity of grains. Journal of Agricultural and Food Chemistry, 50, 61826187.

Agrawal AA (2001). Phenotypic plasticity in the interaction and evolution of species. Science, 294, 321-326.

Baque MA, Lee EJ, Paek KY (2010). Medium salt strength induced changes in growth, physiology and secondary metabolite contentin adventitious roots of Morinda citrifolia: The role of antioxidant enzymes and phenylalanine ammonia lyase. Plant Cell Reports, 29, 685-694.

Bradford MM (1976). A rapid and sensitive method for the quantitation of microgram quantities of protein utilizing the principle of protein-dye binding. Analytical Biochemistry, 72, 248-254.

Brandolini A, Castoldi P, Plizzari L, Hidalgo A (2013). Phenolic acids composition, total polyphenols content and antioxidant activity of Triticum monococcum, Triticum turgidum and Triticum aestivum: A two-years evaluation. Journal of Cereal Science, 58, 123-131.

Campos-Vargas R, Saltveit ME (2002). Involvement of putative chemical wound signals in the induction of phenolic metabolism in wounded lettuce. Physiologia Plantarum, 114, 73-84.

Chaman ME, Copaja SV, Argandoña VH (2003). Relationships between salicylic acid content, phenylalanine ammonialyase (PAL) activity, and resistance of barley to aphid infestation. Journal of Agricultural and Food Chemistry, 51, 2227-2231.

Dicke M, van Poecke RM, de Boer JG (2003). Inducible indirect defence of plants: From mechanisms to ecological functions. Basic and Applied Ecology, 4, 27-42.

Dixon RA, Paiva NL (1995). Stress induced phenylpropanoid metabolism. Plant Cell, 7, 1085-1097.

Fu JM, Huang BG (2001). Involvement of antioxidants and lipid peroxidation in the adaptation of two cool-season grasses to localized drought stress. Environmental and Experimental Botany, 45, 105-114.

Giannopolitis CN, Ries SK (1977). Superoxide dismutases I. Occurrence in higher plants. Plant Physiology, 59, 309-314.

Gill SS, Tuteja N (2010). Reactive oxygen species and antioxidant machinery in abiotic stress tolerance in crop plants. Plant Physiology and Biochemistry, 48, 909-930.

Gogoi R, Singh DV, Srivastava KD (2001). Phenols as a biochemical basis of resistance in wheat against Karnal bunt. Plant Pathology, 50, 470-476.

Haruta M, Pedersen JA, Constabel CP (2001). Polyphenol oxidase and herbivore defense in trembling aspen (Populus tremuloides): cDNA cloning, expression, and potential substrates. Physiologia Plantarum, 112, 552-558.

Hu ZH, Yang D, Shen YB (2009). Difference of phenolic contents in leaves of Populus simonii $\times P$. pyramidalis "Opera 8277” cuttings induced by various damages. Acta Botanica Boreali-Occidentalia Sinica, 29, 332-337. (in Chinese with English abstract) [胡增辉, 杨迪, 沈应柏 (2009). 不同损伤形式诱导合作杨叶片中酚类物质含量的差异. 西北植物学报, 29, 332-337.]

Jiang Y, Joyce DC (2003). ABA effects on ethylene production, PAL activity, anthocyanin and phenolic contents of strawberry fruit. Plant Growth Regulation, 39, 171-174.

Kessler A, Baldwin IT (2002). Plant responses to insect herbivory: The emerging molecular analysis. Annual Review of Plant Biology, 53, 299-328.

Kestring D, Menezes LCCR, Tomaz CA, Lima G, Rossi MN (2009). Relationship among phenolic contents, seed predation, and physical seed traits in Mimosa bimucronata plants. Journal of Plant Biology, 52, 569-576.

Koussevitzky S, Ne'eman E, Harel E (2004). Import of polyphenol oxidase by chloroplasts is enhanced by methyl jasmonate. Planta, 219, 412-419.

Kováčik J, Klejdus B, Hedbavny J, Bačkor M (2010). Effect of copper and salicylic acid on phenolic metabolites and free amino acids in Scenedesmus quadricauda (Chlorophyceae). Plant Science, 178, 307-311.

Lachman J, Amouz K, Šulc M, Orsák M, Pivec V, Hejtmánková A, Dvorák P, Cepl J (2009). Cultivar differences of total anthocyanins and anthocyanidins in red and purplefleshed potatoes and their relation to antioxidant activity. Food Chemistry, 114, 836-843.

Latha P, Anand T, Ragupathi N, Prakasam V, Samiyappan R (2009). Antimicrobial activity of plant extracts and induction of systemic resistance in tomato plants by mixtures of PGPR strains and Zimmu leaf extract against Alternaria solani. Biological Control, 50, 85-93.

Li YQ, Sun YJ, Zhang TH, Zhao AF, Lian J (2011). Structural characteristics of Artemisia frigid community at different succession stages in Horqin Sandy Land. Chinese Journal of Applied Ecology, 22, 1725-1730. (in Chinese with English abstract) [李衍青, 孙英杰, 张铜会, 赵爱芬, 连杰 (2011). 科尔沁沙地不同演替阶段冷蒿群落的结构特征. 应用生态学报, 22, 1725-1730.]

Lin KM, Ye FM, Lin Y, Li QS (2010). Research advances of phenolic functional mechanisms in soils and plants. Chinese Journal of Eco-Agriculture, 18, 1130-1137. (in Chinese with English abstract) [林开敏, 叶发茂, 林艳, 李卿 参 (2010). 酚类物质对土壤和植物的作用机制研究进 展. 中国生态农业学报, 18, 1130-1137.]

Liu NN, Tian QY, Zhang WH (2014). Comparison of adaptive strategies to phosphorus-deficient soil between dominant

www.plant-ecology.com 
species Artemisia frigida and Stipa krylovii in typical steppe of Nei Mongol. Chinese Journal of Plant Ecology, 38, 905-915. (in Chinese with English abstract) [刘娜娜, 田秋英, 张文浩 (2014). 内蒙古典型草原优势种冷蒿和 克氏针茅对土壤低磷环境适应策略的比较. 植物生态 学报, 38, 905-915.]

Liu R, Wang ZY, Li TT, Wang F, An J (2014). The role of chitosan in polyphenols accumulation and induction of defense enzymes in Pinus koraiensis seedlings. Chinese Journal of Plant Ecology, 38, 749-756. (in Chinese with English abstract) [刘冉, 王振宇, 李婷婷, 王芳, 安静 (2014). 壳聚糖对红松幼苗多酚积累和抗氧化防御酶的 诱导作用. 植物生态学报, 38, 749-756.]

Matkowski A (2006). Plant Phenolic Metabolites as Antioxidants and Mutagenesis Inhibitors. IOS Press, Amsterdam.

Meng JF, Fang YL, Qin MY, Zhuang XF, Zhang ZW (2012). Varietal differences among the phenolic profiles and antioxidant properties of four cultivars of spine grape (Vitis davidii Foex) in Chongyi County (China). Food Chemistry, 134, 2049-2056.

Nicholson RL, Hammerschmidt R (1992). Phenolic compounds and their role in disease resistance. Annual Review of Phytopathology, 30, 369-389.

Nordberg J, Arner ES (2001). Reactive oxygen species, antioxidants, and the mammalian thioredoxin system. Free Radical Biology and Medicine, 31, 1287-1312.

Paul S, Gooding CB (2001). Molecular cloning and characterization of banana fruit polyphenol oxidase. Planta, 213, 748-757.

Puthoff DP, Smigocki AC (2007). Insect feeding-induced differential expression of Beta vulgaris root genes and their regulation by defense-associated signals. Plant Cell Reports, 26, 71-84.

Robbins RJ (2003). Phenolic acids in foods: An overview of analytical methodology. Journal of Agricultural and Food Chemistry, 51, 2866-2887.

Sharma P, Jha AB, Dubey RS, Pessarakli M (2012). Reactive oxygen species, oxidative damage, and antioxidative defense mechanism in plants under stressful conditions. Journal of Botany, 2012, 1-26.

Tan BK, Harris ND (1995). Maillard reaction products inhibit apple polyphenoloxidase. Food Chemistry, 53, 267-273.

van Poecke RMP, Dicke M (2004). Indirect defence of plants against herbivores: Using Arabidopsis thaliana as a model plant. Plant Biology, 6, 387-401.

Wang J, Yang C, Han WQ, Liu ML (2003). Effects on watersoluble carbohydrate of Artemisia frigida under different defoliation intensities. Acta Ecologica Sinica, 23, 908-913. (in Chinese with English abstract) [王静, 杨持, 韩文权, 刘美玲 (2003). 刏割强度对冷高可溶性碳水化
合物的影响. 生态学报, 23, 908-913.]

Wang Q, Yan SC, Jin H, Wang YJ (2012). Systemic induction of defensive enzymes in needles of Larix gmelinii seedlings in wounded conditions. Journal of Northeast Forestry University, 40(9), 77-80. (in Chinese with English abstract) [王琪, 严善春, 金虎, 王艳军 (2012). 叶损伤 对兴安落叶松防御酶活性的系统诱导. 东北林业大学 学报, 40(9), 77-80.]

Wang SP, Li YH, Wang YF, Chen ZZ (2001). Influence of different stocking rates on plant diversity of Artemisia frigida community in inner mongolia steppe. Acta Botanica Sinica, 43, 89-96. (in Chinese with English abstract) [汪诗平, 李永宏, 王艳芬, 陈佐忠 (2001). 不 同放牧率对内蒙古冷蒿草原植物多样性的影响. 植物 学报, 43, 89-96.]

Wang W, Liu ZL, Hao DY, Liang CZ (1996). Research on the restoring succession of the degenerated grassland in Inner Mongolia II. Analysis of the restoring processes. Acta Phytoecologica Sinica, 20, 460-471. (in Chinese with English abstract) [王炜, 刘钟龄, 郝敦元, 梁存柱 (1996). 内蒙古草原退化群落恢复演替的研究II. 恢复 演替时间进程的分析. 植物生态学报, 20, 460-471.]

Winkel-Shirley B (1999). Evidence for enzyme complexes in the phenylpropanoid and flavonoid pathways. Physiologia Plantarum, 107, 142-149.

Xu GH, Guan RF, Ye XQ, Chen JC, Liu DH (2008). Composition and distribution of phenolic acids in satsuma mandarin (Citrus unshiu Marc.) during maturity. Food Science, 29(2), 137-141. (in Chinese with English abstract) [徐贵华, 关荣发, 叶兴乾, 陈健初, 刘东红 (2008). 不同成熟期蜜桔中酚酸的组成与分布. 食品科 学, 29(2), 137-141.]

Yan SC, Yuan HE, Wang Q, Wang YJ (2010). Quantitative changes of phenolic acids in Larix gmelinii needles induced by leaf damage. Chinese Journal of Applied Ecology, 21, 1000-1006. (in Chinese with English abstract) [严善春, 袁红娥, 王琪, 王艳军 (2010). 叶损 伤诱导兴安落叶松针叶中 10 种酚酸的变化. 应用生态 学报, 21, 1000-1006.]

Zhang JE, Liu WG, Chen JQ, Shi YC, Cai YF (2005). Effects of different cutting intensities on above- and underground growth of Stylosanthes guianensis. Chinese Journal of Applied Ecology, 16, 1740-1744. (in Chinese with English abstract) [章家恩, 刘文高, 陈景青, 施耀才, 蔡燕飞 (2005). 不同刚割强度对牧草地上部和地下部生长性状 的影响. 应用生态学报, 16, 1740-1744.]

Zhang RM, Wang YZ, Hou P, Wen GS, Gao Y (2010). Physiological responses to allelopathy of aquatic stem and leaf extract of Artemisia frigida in seedling of several 
pasture plants. Acta Ecologica Sinica, 30, 2197-2204. (in Chinese with English abstract) [张汝民, 王玉芝, 侯平, 温国胜, 高岩 (2010). 几种牧草幼苗对冷蒿茎叶水浸提 液化感作用的生理响应. 生态学报, 30, 2197-2204.]

Zhang RM, Zhang WG, Zuo ZJ, Li R, Wu JH, Gao Y (2014). Inhibition effects of volatile organic compounds from Artemisia frigida Willd. on the pasture grass intake by lambs. Small Ruminant Research, 121, 248-254.

Zhao K, Baoyin T (2014). Effect of seasonal grazing use on productivity of grassland community. Chinese Journal of Grassland, 36(1), 109-115. (in Chinese with English abstract) [赵康, 宝音陶格涛 (2014). 季节性放牧利用对 典型草原群落生产力的影响. 中国草地学报, 36(1),
109-115.]

Zuo ZJ, Zhang RM, Wang Y, Wen GS, Hou P, Gao Y (2010). The composition of volatile organic compounds (VOCs) emitted from damaged Artemisia frigida Willd. plants and their effects on root growth and development of pasture plants. Acta Ecologica Sinica, 30, 5131-5139. (in Chinese with English abstract) [左照江, 张汝民, 王勇, 温国胜, 侯平，高岩 (2010). 损伤冷蒿挥发性有机化合物 (VOCs)成分分析及其对牧草根系生长发育的影响. 生 态学报, 30, 5131-5139.]

责任编委: 赵 平 责任编辑: 李 敏

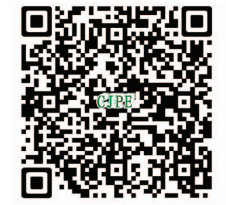

植物生态学报官网

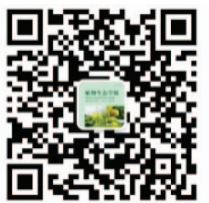

微信订阅号

期刊及学科

相关信息发布

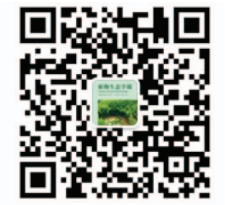

微信服务号

稿件状态查询

全文检索浏览 